Sri Lanka J. Aquat. Sci. 11 (2006): 27-42

\title{
Selective control of marine algal species by electrolysis treatment
}

\author{
SAMAN WIJESEKARA. R.G, NAKAO NOMURA AND \\ MASA TOSHI MA TSUMURA*
}

Graduate School of Life and Environmental Sciences, University of Tsukuba, Tennodai 1-1-1, Tsukuba City, Ibaraki 305-0006, Japan

*Corresponding author (E-mail: aquacel@sakura.cc.tsukuba.ac.jp)

\begin{abstract}
This paper deals with the application of electrolysis technology for the selective control of marine algal species. The sensitivity of different marine algal species to electrolysis may be different due to their size and structural differences. Electrolysis experiments were conducted using four algal species, namely Chlorella spp., Chaetoceros spp., Isochrysis spp. and Tetraselmis spp. Batch and continuous runs were conducted from 0-7 minutes and 0-80 minutes, respectively. Drastic depletion of algal cell number was not observed during batch electrolysis. However, fluorescein diacetate and propidium iodide staining showed significant algal mortality. Different sensitivities were also observed for similar electrolysis conditions. Continuous electrolysis data revealed almost no survival forChlorella spp. at 80 minute electrolysis time while survival forIsochrysis spp. was around $60 \%$ at similar conditions. Results indicated that the green algaeChlorella spp. is the most sensitive while the brown algaeIsochrysis spp. is the most resistant among the four species studied. More importantly, this confirmed that the beneficial marine algae Isochrysis spp. can be allowed to dominate by selectively limiting the growth of three other algal species tested in this work through electrolysis treatment.
\end{abstract}

\section{Introduction}

Phytoplankton over blooming is a common phenomenon in intensive shrimp aquaculture. Various physical, chemical and biological processes as well as management activities are usually involved in the occurrence of phytoplankton over-blooming. Excess phytoplankton creates an aquatic environment that is unsuitable for cultured shrimp. They also compete with dissolve oxygen especially during night and cloudy weather thus creating 
dissolved oxygen (DO) deficiencies. DO is one of the most important water quality parameters in intensive shrimp grow-out systems. Lack of dissolve oxygen can give detrimental effect on shrimp population. Massive algal dieoff not only deteriorates water quality but also leads to the proliferation of pathogenic bacteria. It has therefore remained as one of the serious problems in intensive shrimp cultivation (Matsumura et al. 2001). Some of the phytoplankton may also produce phyto-toxins which may weaken the shrimp performance or cause mortalities (Jan 2002). Organic matter produced in phytoplankton photosynthesis adds to the pollution loads in shrimp ponds leading to the accumulation of ammonia, phosphorus and organic matter on pond bottom (Boyd 1995).

Dominance of certain algal species may also occur unexpectedly in shrimp grow-out ponds from time to time. This may be either beneficial or non beneficial for marine shrimp cultivation depending on the type of algal cells that proliferate. Water exchange is one of the most common management practices widely applied to control algal over-blooming in shrimp grow-out ponds. However, water exchange is dependent on several other related factors such as salinity, availability of seawater, water quality of the source water and availability of power supply. It is believed that beneficial algal blooms and appropriate densities are some of the key factors for successful shrimp production. Therefore, development of effective algal control techniques would be important to control algal over blooming.

Various chemical, mechanical and biological techniques have been reported for controlling algal growth. However, most of these methods are ineffective for selective phytoplankton control. Electro-oxidation may be a suitable process for this purpose. Electrolysis produces powerful oxidizers and it has been applied for the disinfection of drinking water and for wastewater management such as the removal of ammonia and ammonia compounds from brine wastewater (Vlyssides et al. 2002; Alfafara et al. 2004). This technology has also been applied for disinfection of seawater for hatchery aquaculture (Jorquera et al. 2002) as well as for the flocculation and removal of micro-algae from drinking water (Poelman et al. 1997) and eutrophied lakes (Alfafara et al. 2002). However, electrolysis has not yet been applied to control marine algal species in shrimp grow-out ponds. This paper attempts to describe the effect of electrolysis on different marine algal species and to find out suitable electrolysis conditions to control their growth. Specifically, the possibility of applying electrolysis to limit the growth of non-beneficial algae while allowing beneficial algae to proliferate is the major target of this research.

\section{Materials and Methods}

\section{Preparation of algal cultures}

Pure algal cultures were isolated from shrimp culture ponds in Thailand, through Kasetsart University. They belong to four different classes, 
namely Chlorella spp. (Chlorophyceae), Tetraselmis spp. (Prasinophyceae), Isochrysis spp. (Haptophyceae) and Chaetoceros spp. (Bacillariophyceae). The selected species include green and brown algae of different size categories. Chlorella spp. is the smallest $(2.8 \mu \mathrm{m})$ and the Tetraselmis spp. is the largest $(10-15 \mu \mathrm{m})$ among the species studied.Chaetoceros spp. and Isochrysis spp. range from 4 to $6 \mu \mathrm{m}$ and from 3 to $5 \mu \mathrm{m}$, respectively. The above algal species were selected to represent different classes and size categories. They are some of the most abundant algal species in marine shrimp ponds. Apart from these species, Nitzchia, Oscillatoriya, Skeletonema, Cyclotella, Thalassionema, Chrococcous, Rhizosolenia, Fragillaria, Trichodesmium and licmophora spp. are some of the cooccurring species in shrimp ponds.

Seawater $(30 \mathrm{ppt})$ was prepared with artificial seawater powder (Marine Art Japan). It was filtered through Whatman $47 \mathrm{~mm}$ glass micro fiber filter papers. The artificial seawater was sterilized at $121^{\circ} \mathrm{C}$ for 15 minutes and cooled down to room temperature before inoculation. Sterilized seawater was enriched with Daigo's IMK medium, (Wako Pure Chemical Industries Ltd, Japan) according to the manufacturer's instruction. Seawater enrichment and algal inoculation procedures were conducted in a clean bench to avoid contamination. Glass test tubes of $50 \mathrm{ml}$ were used to maintain stock algal cultures and $1000 \mathrm{ml}$ conical flasks were used in the first algal multiplication stage. These cultures were incubated in a growth cabinet CFC $0 \%$ (SANYO Company, Japan) under a controlled environment of $25 \mathrm{C}$ temperature, $\mathrm{pH} 8.0-8.2$ and a light intensity of 2500 Lux (Lavens and Sorgeloos 1996). Glass tanks of 20 liter capacity were used during the second algal multiplication stage. Algal cultures were sufficiently aerated with aquarium air pumps (New CALM Five Plan Taiwan) equipped with 0.20 $\mu \mathrm{m}$ Advantech cellulose acetate filters (Toyo Roshi Kaisha Ltd, Japan) to supply clean air.

\section{Batch electrolysis system}

Batch experiments were conducted in $1000 \mathrm{ml}$ glass beakers. The beaker was filled with $1000 \mathrm{ml}$ algae solution cultured in the laboratory. The algal solution had a cell concentration of $5 \times 10^{5}$ algal cells $\mathrm{ml}^{-1}$ and a salinity of 30 ppt. The anode used in this work was made from titanium base metal sintered with $\mathrm{Pt}, \mathrm{Ru}$ and Pd Mode 2 (Ishifuku Metal Industry Co., Ltd., Japan) while the cathode was of stainless steel (Model SUS 304, Nilaco Corporation, Japan). The anode and cathode has similar dimensions ( $15 \times 5 \times$ $0.1 \mathrm{~cm}$ ) and they were fixed to utilize only $15 \mathrm{~cm}^{2}$ of area for electrolysis. Spacing between the anode and cathode was $5 \mathrm{~mm}$. A magnetic stirrer (Iuchi model HS-3E, Iuchi Company, Japan) was operated at $500 \mathrm{rpm}$ for algal suspension mixing. A DC power supply unit EX-750L2 (T AKASAGO LTD, Japan) was connected to the anode and cathode (Fig. 1) and a constant current of $0.1 \mathrm{~A}$ was supplied to the system by automatically adjusting the voltage between $2.5-2.6 \mathrm{~V}$. Each electrolysis run was conducted for 7 minutes and water samples for analysis were collected before electrolysis and at 1 minute 
intervals. Samples were withdrawn by a syringe at a point $2-3 \mathrm{~cm}$ below the medium surface. Samples for algal cell count (as well as for staining in order to calculate live and dead algal percentages) were neutralized just after sampling with $10 \% \mathrm{Na}_{2} \mathrm{~S}_{2} \mathrm{O}_{3}$ at a dosage of $0.1 \mathrm{ml}$ per $\mathrm{ml}$ of sample.

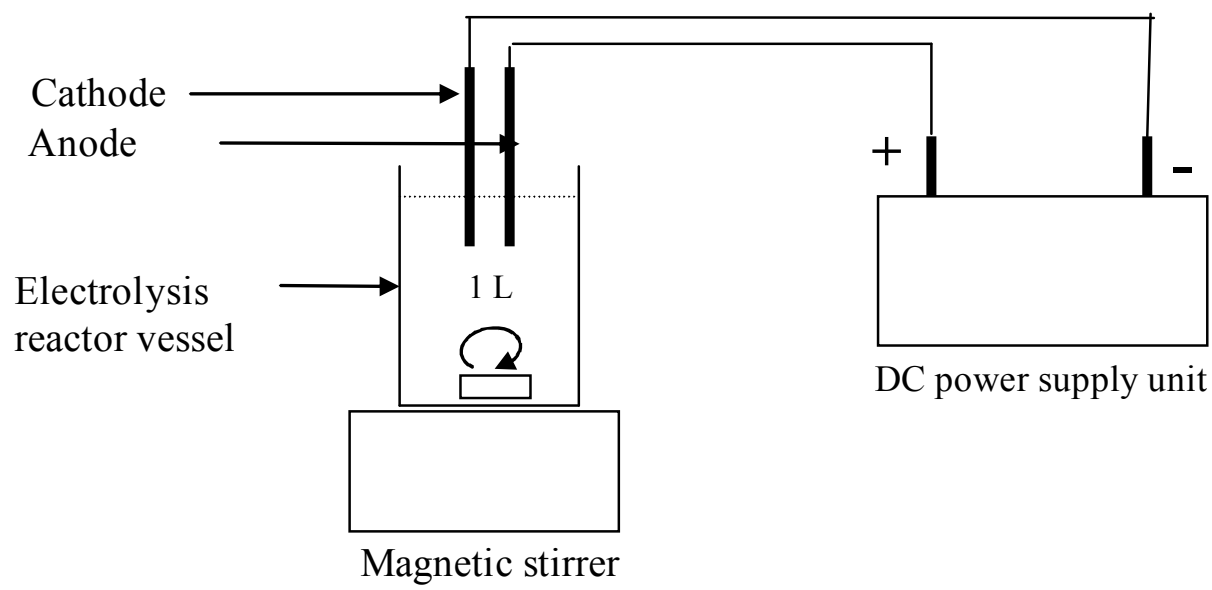

Figure 1. Schematic diagram of the batch culture electrolysis system. 1 liter capacity reactor vessel is filled with algal suspension. Anode and cathode are fixed to utilize $15 \mathrm{~cm}^{2}$ areas of both electrodes.

\section{Continuous electrolysis system}

Figure 2 shows the schematic of the continuous electrolysis system. The working volume of the electrolysis vessel is 2 liter. The electrodes composition, connections, power supply unit, voltage and current were exactly the same as that of the batch system. An additional magnetic stirrer was used to mix the algal reservoir. A Master Flex 7024-20 (Cole-Parmer Instrument Company Illinois, USA) pump was used to transfer algal solution

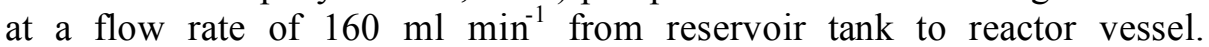
Continuous runs were conducted for $80 \mathrm{~min}$ at a retention time of $12.5 \mathrm{~min}$. Fifty $\mathrm{ml}$ of samples for analysis were collected from the overflow of the electrolysis reactor vessel every 10 minutes. Parameter analysis and methods for sample preservation were similar to the batch culture system. During continuous runs however, sensitivities to electrolysis of only two algal species namely Chlorella spp. and Isochrysis spp. were evaluated. (Chlorella spp. is the most sensitive whileIsochrysis spp. is the most resistant species based on the batch electrolysis data). Initial algal concentrations applied were also similar to the batch runs. 


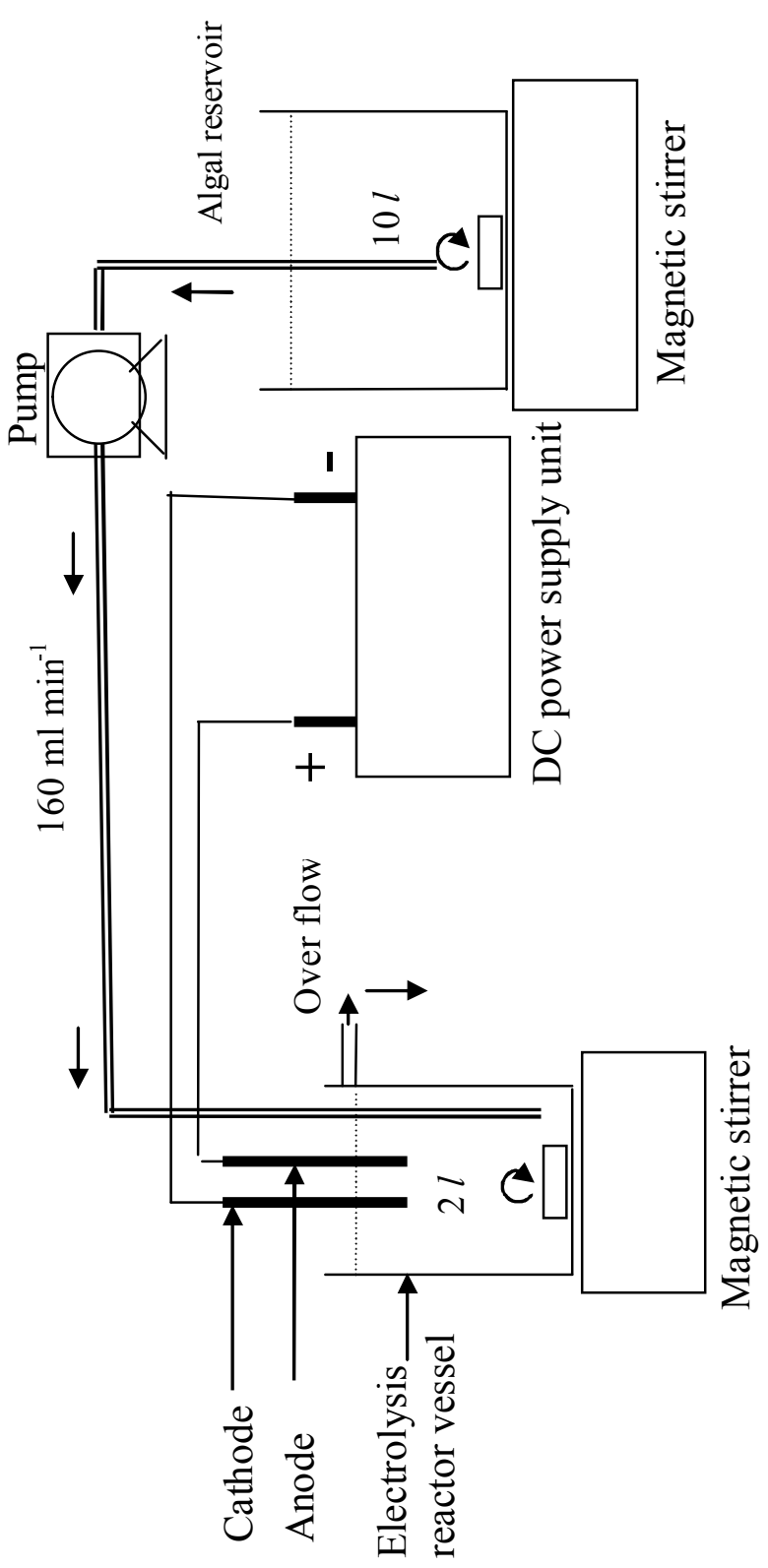

Figure 2. Schematic diagram of the continuous electrolysis system. It consists of two liter capacity reactor vessel and 10 liter capacity reservoir vessel. Fresh algal suspension is pumped to the reactor vessel continuously by a standard pump. Electrodes are fixed to utilize $15 \mathrm{~cm}^{2}$ areas of both electrodes. 


\section{Parameter analysis}

Both the total and free chlorine were measured using a chlorine tester H1 93711 (HANNA Instruments, Japan). Salinity and $\mathrm{pH}$ as well as temperature were determined by a hand refractometer (A T AGO Company, Japan) and pH meter (TPX 90), respectively. The Total Residual Oxidant (TRO) was determined by colourimetry at $352 \mathrm{~nm}$ wave length (Sugita et al. 1992) using a Hitachi U-2000 spectrophotometer (Hitachi Company, Japan).

\section{Algal cell count}

Algal cells were counted before and after electrolysis. The samples were neutralized with $10 \% \mathrm{Na}_{2} \mathrm{~S}_{2} \mathrm{O}_{3}$ at a dosage of $0.1 \mathrm{ml}$ for every $\mathrm{ml}$ of sample water to neutralize the TRO to stop further reactions with algal cells. All algal samples were counted in two replicates using a Haemacytometer under the light microscope CK2 (Olympus Optical Co, LTD, Japan) at $600 \mathrm{x}$ magnification (Granvil \& Joe 1993).

\section{Statistical analysis}

Single factor and two factor ANOVA were performed for the interpretation of results.

\section{Estimation of survival and dead algal percentages}

Fluorescein Diacetate (FDA) and Propidium Iodide (PI) staining was applied to differentiate dead and live algal cells (Aoyagi \& Tanaka 1994; Saha et al. 2003). Successful application of FDA staining together with fluorometry for the measurement of viable cells of plant has been reported. Viability results of fluorometry have been found to be proportional to their colony-forming efficiency, suggesting the accurate identification of viable cell by this process (Aoyagi \& Tanaka 1994). In principle, live algal cells emit green fluorescence while dead algal cells emit red fluorescence with FDA and PI double staining. During FDA staining, FDA penetrates both the live and dead cells due to its hydrophobicity. The FDA is then hydrolyzed by esterase activity in the live cells to emit green fluorescence at wave length of $520 \mathrm{~nm}$ (Fig. 3). As there is no esterase activity in dead cells, green fluorescence is not emitted. During PI staining, PI does not penetrate into intact viable cells due to its hydrophilicity, but it does in dead cells through membranes that were damaged during electrolysis. PI then binds to DNA and RNA of dead cells and emits a red fluorescence at $617 \mathrm{~nm}$.

During algal counting, all sampling tubes used were covered to avoid exposure to light. Forty $\mu 1$ of FDA was mixed with $10 \mathrm{ml}$ Dulbeco's PBS (-) solution (Wako, Japan) in a test tube and the mixture was kept in ice. Thirty $\mu 1$ of PI solution was added into $100 \mu$ of this prepared FDA and PBS solution and then mixed well. Finally $200 \mu \mathrm{l}$ of algae was added to the resulting solution, mixed thoroughly and allowed to react for 6 minutes. The mixture was kept in ice for another 10 minutes. Cells in each sample were counted using a Leica DMR Fluorescence microscope at $600 \mathrm{x}$ magnification. The percentages of live and dead cells were determined by dividing the 
number of dead and live cells respectively, by the total cell number. Two replicates were made to estimate viable and dead cell percentages.

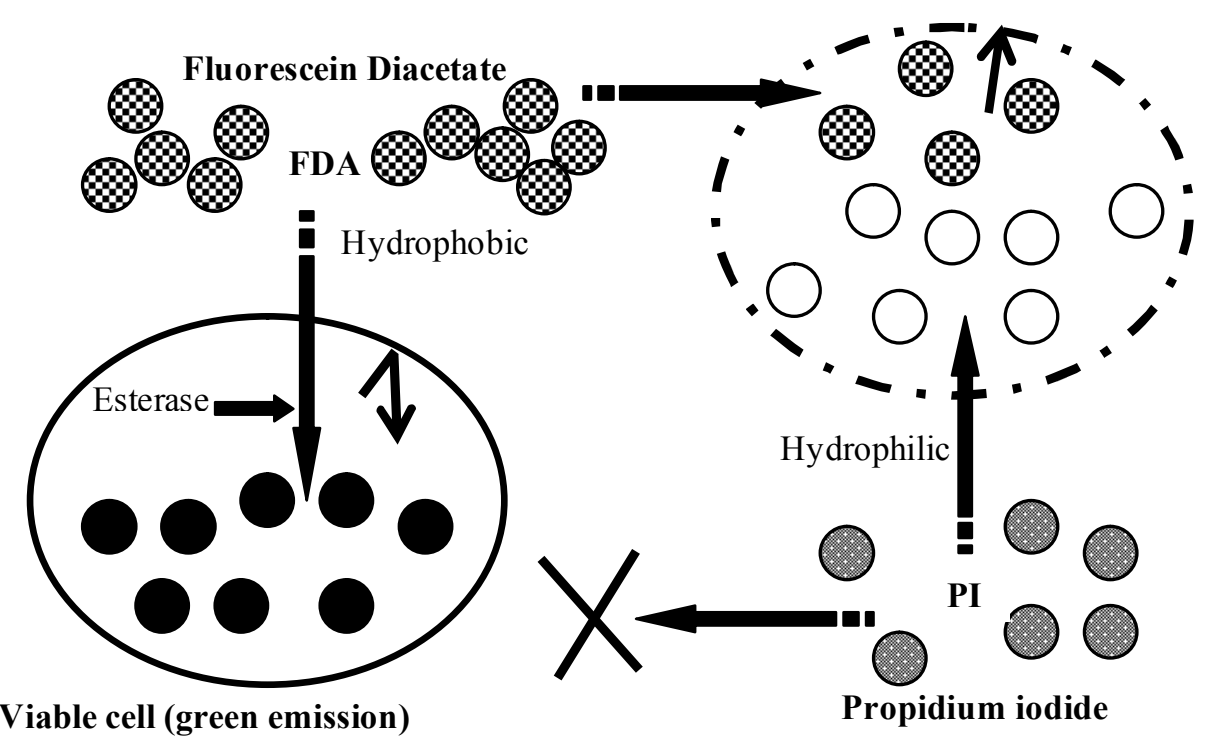

Figure 3. Mechanism of FDA and PI algal staining procedure. Viable algal cells emit green and dead cells emit red florescence. FDA penetrates both viable and dead cells but only viable cells emit green florescence. FDA produced in viable cell does not leak out from the cell as there is no damage in the cell membrane. PI penetrates into dead cells only and then binds with DNA and RNA emitting red florescence.

\section{Results and Discussion}

\section{Batch algal electrolysis system}

Initial algal cell concentration in this experiment was maintained at 5 x $10^{5}$ cells ml ${ }^{-1}$ to simulate cell concentrations in intensive shrimp grow-out ponds. Upon electrolysis, cell concentration started to decline from the first minute for all algal species. Algal cell concentration declined by about $50 \%$ during the final minute of electrolysis (Fig. 4).This decline of cell amount may be attributed to their lyses by $\mathrm{HOBr}$ and $\mathrm{HOCl}$ oxidants produced during the electrolysis process. Reduction of algal cell number was almost the same for all the species. Statistical analysis showed that reduction of algal cell count with respect to electrolysis time was significant at $5 \%$ level. Just by total cell count, there appears to be no clear difference in terms of their response to electrolysis. Complete algal cell lyses were not observed under the present electrolysis conditions and this may be due to the structural properties of the algal cells. 


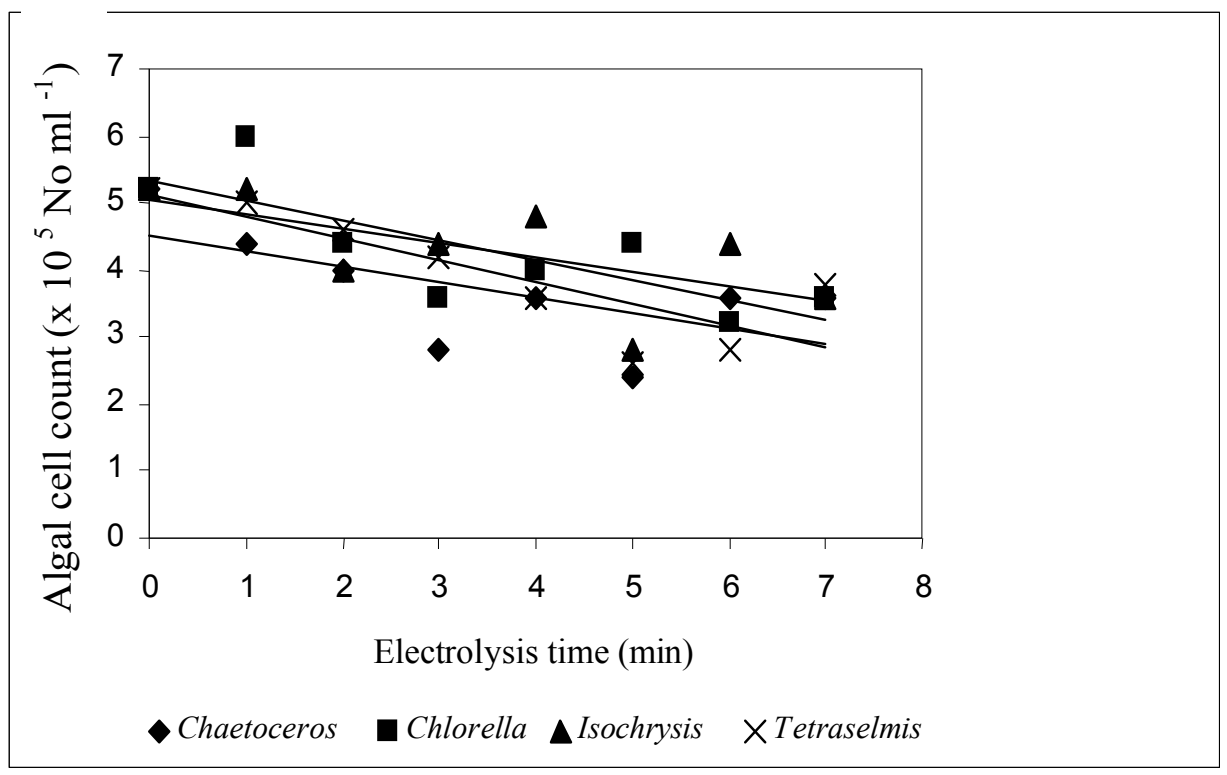

Figure 4. Effect of electrolysis on algal cell count of different marine algal species during batch culture electrolysis experiment. This describes algal cell counts before electrolysis and after every minute. Electrolysis reactor volume $1000 \mathrm{ml}$, Current $0.1 \mathrm{~A}$ and voltage $2.5 \mathrm{~V}$.

\section{Sensitivity of different algal species}

Based from FDA and PI staining results, batch electrolysis interestingly showed different sensitivities of algal cells (Fig. 5). Specifically FDA and PI double staining were able to differentiate clearly the viable from non viable cells under the fluorescence microscope. Algal survival of Chlorella spp., Chaetoceros spp. and Tetraselmis spp. dropped to zero after 1,2 and 3 minutes of treatment, respectively. However, survival of Isochrysis spp. dropped only gradually to $50 \%$ even after 7 minutes of electrolysis. Clearly, some differences with regards to the sensitivity of the algal cells to electrolysis can be observed. The most resistant algal species appears to be Isochrysis spp. followed by Tetraselmis spp. and then Chaetoceros spp. while the most sensitive algal species is Chlorella spp. Electrolysis data of marine algaeSkeletonema from past researchers have also shown similarly low resistance to electrolysis (Whanchai et al. 2002). Chlorophyll-a concentration reduction to its minimum concentration after four minutes of electrolysis has been observed thus indicating its lower resistance than Isochrysis spp.

To explain its resistance to electrolysis, Isochrysis spp. has been reported to contain unusually very long chains of unsaturated methyl and ethyl alkenones and methyl and ethyl esters of 36:2 fatty acid (Volkman et al. 1980). The role of these compounds inIsochrysis spp. is not known, but it seems likely that they are associated with membrane structure (Dunstan et al. 1993). Numerous literature reports confirm that the sensitivity of different marine algal species and aquatic animals to other chemical contaminants such 
as heavy metals may vary due to different cell wall composition. It has been shown that the sensitivity ofIsochrysis spp. and Perna viridis is different for same heavy metals (Y ap et al. 2004). Chromium toxicity test on Chlorella spp. has also shown positive results although chromium has been found to stimulate the growth of certain plants and algae (Zsolt and Arpad 2002). Furthermore, investigations (Maria et al. 2001) have shown a significant decrease in the content of both lipid and water soluble antioxidants that might contribute to oxidative stress in theChlorella spp. cells. These works suggest that Chlorella spp. may possess a lower resistance to oxidants such as $\mathrm{HOBr}$ and $\mathrm{HOCl}$, which are produced during electrolysis. More detailed discussions on this aspect will be made in a later section regarding continuous electrolysis system.

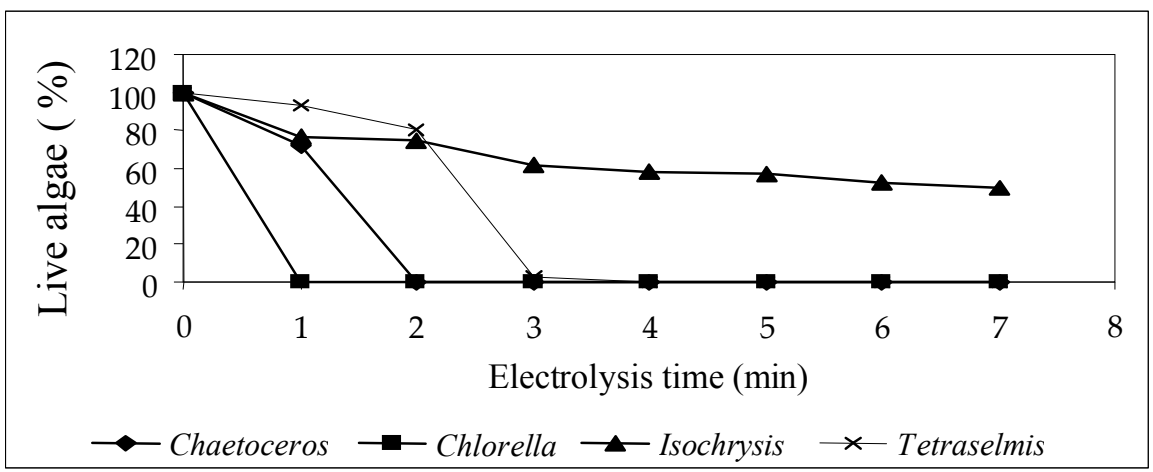

Figure 5. Effect of electrolysis on different marine algal species. Live algal percentages estimated by FDA and PI double staining before and after electrolysis were plotted against electrolysis retention time. Electrolysis reactor volume $1000 \mathrm{ml}$, Current $0.1 \mathrm{~A}$ and voltage $2.5 \mathrm{~V}$.

In any case, the above sensitivity data from batch experiments establishes the ability of electrolysis to selectively control the growth of nonbeneficial algal cells such asChlorella spp. in shrimp ponds. Most Chlorella species have rigid cell wall with glucosamine as its major component (V olkman et al. 1980). With this property, it cannot be directly utilized by fish fry structure (Dunstan et al. 1993) so that it is considered non-beneficial algae for aquaculture with regards to its nutritive value. Previous researchers have given Chlorella spp. the lowest ranking based on the utilization shrimp by hatchery operators. (Higher ranks are given to Isochrysis spp., Chaetoceros spp. and Tetraselmis spp.) (Lavens \& Sorgeloos 1996). Interestingly, the present experimental results show thatChlorella spp. is very sensitive to electrolysis (Fig. 7). Its growth can therefore be controlled by simply changing the electrolysis conditions. In the case oflsochrysis spp., it is widely used in commercial mariculture as feeds as well as for rearing marine invertebrates due to its high content of long chain 
polyunsaturated fatty acids (PUFAs) (Zsolt and Arpad 2002; Y ap et al. 2004). Hence, it can be considered beneficial. As desired/sochrysis spp. displayed higher resistance to electrolysis.

\section{Water quality parameters}

The above discussions highlight the ability of electrolysis to selectively control the growth of certain algal cells. This can be attributed to the differences in their cellular structures, which then results to different responses to oxidizing agents during electrolysis. To confirm this phenomenon detailed evaluations on the fate of oxidizing agents generated during electrolysis runs was also studied. In general, Total Residual Oxidants (TRO) such as hypochlorous and hypobromous acid ( $\mathrm{HOCl}$ and $\mathrm{HOBr}$ ) are the predominant species formed during seawater electrolysis. Chlorine gas is also a major oxidant as the seawater contains $\mathrm{Cl}$. These TROs are responsible for the break down of organic matter as well as ammonia present in the medium (Alfafara et al. 2004).

Figure 5 shows that the survival of Chlorella spp. dropped to zero during the first minute. At this point, electrolysis may have damaged the algal cells so that cell content may leak out resulting to increased organic content of the solution. TRO can then react with these organics. Figure 6 shows the time course of TRO during electrolysis. For all runs, low TRO values were observed in the initial stage of electrolysis. This indicates its possible reaction with organics. As electrolysis progresses, organics are depleted so that TROs concentration started to increase. In the case ofIsochrysis spp. TRO started to increase at the third minute as algal survival decreased to $60 \%$ and then was maintained at around $50 \%$ afterwards. For Chaetoceros spp., its survival dropped to zero at the second minute so that TRO began to rise from this time. However, it seems that organic matter ofChaetoceros spp. easily reacts with TROs as compared to other two algal species as it showed lower TRO values throughout the electrolysis period. Finally, for Tetraselmis spp. its survival dropped to zero at a much later time in response to the increased TRO during that period. TRO values of control experiment are significantly higher than all the algal systems studied and this indicates that TROs in this case readily accumulate as there are no organic compounds to oxidize. The batch electrolysis results also showed that organic matter preferentially reacts with TRO first before reacting with chlorine. Figure 6 shows that TRO values readily decreased during the first few minutes upon reacting with organic matter released from algal cells.

\section{Continuous electrolysis system Effect on algal survival}

The survival data of the two algal species Chorella spp. and Isochrysis spp. in response to continuous electrolysis showed very remarkable results. Algal survival of Chlorella spp. dropped nearly to $50 \%$ within 10 minutes and then to around $15 \%$ in 20 minutes. It decreased further gradually and was finally maintained at close to $0 \%$ at steady state after 50 
minutes. In the case of Isochrysis spp., a much slower decline in survival percent was observed. A higher survival of approximately $60 \%$ at steady state after 50 minutes was also evident (Fig. 7). This result showing the higher resistance of Isochrysis spp. to electrolysis as compared to Chlorella spp. is in accordance with the batch data previously discussed. Statistical analysis also proved that there is a significant difference in algal survival between Chorella spp. and Isochrysis spp with electrolysis time at 5\% level, since F computed value (20.68) is greater than F critical (4.49). Again, to explain the above findings, it is important to characterize the algae in terms of their cell wall compositions. The marine algaelsochrysis spp. belongs to the division haptophyta and class haptophycea. Cells of this class have a special cell wall structure. The cell surface is covered with tiny scales or granules of organic materials (cellulose) in addition to calcified scales called cocoliths. The layers of scales are glued together by a coating of complex acidic polysaccharide (Van den et al. 1995). This special nature of cell wall in haptophycea class of algae may create high resistance to chemicals such as the oxidants formed during electrolysis. Indeed, past workers have applied electrolysis at a current of 1.0-4.0 A for the disinfection of micro-algae solution containing Isochrysis galbana without deleterious effect on its growth rate (Milko et al. 2002). They have also shown significantly higher growth rate in seawater subjected to electrolysis treatment. It has also been found that the induction of heat shock protein (hsp60) inIsochrysis galbana is significantly higher upon exposure to sub-lethal preparation of dispersant and Prudhoe Bay crude oil (Wolfe 1999). The amount of this protein increases with temperature. These properties may confirm the ability of Isochrysis spp. to survive against stressful environmental conditions. As previously mentioned, cell walls of Chlorella species on the other hand consist of rigid cell wall composed of glucosamine, displaying no anisotrophic structure. It does not contain polysaccharides unlike the cell walls of most of other algae (Hiroshi 1985). Due to the absence of polysaccharides, it has a high affinity for $\mathrm{HOBr}$ and $\mathrm{HOCl}$ oxidants. (In contrast, the polysaccharides in Isochrysis spp. cell wall can make it less reactive with TRO, thus further enhancing its resistance to electrolysis.)

Indeed, both the batch and the continuous electrolysis experimental results clearly confirm that Isochrysis spp. is more resistant to electrolysis than Chlorella spp. As an important finding of this research, selective control of algal cell growth through electrolysis can be attained by simply manipulating the electric current in addition to flow rate and retention time. Specifically, beneficial cells such as Isochrysis spp. can be allowed to dominate by limiting the growth of non-beneficial cells such aschlorella spp. through electrolysis. Possibility of risk of dominating toxic algal bloom due to electrolysis treatment was not studied in this work. Toxic algal bloom such as blue green algae usually occurs in shrimp ponds at very low salinity conditions, however, electrolysis may not be effective at low salinity conditions. 


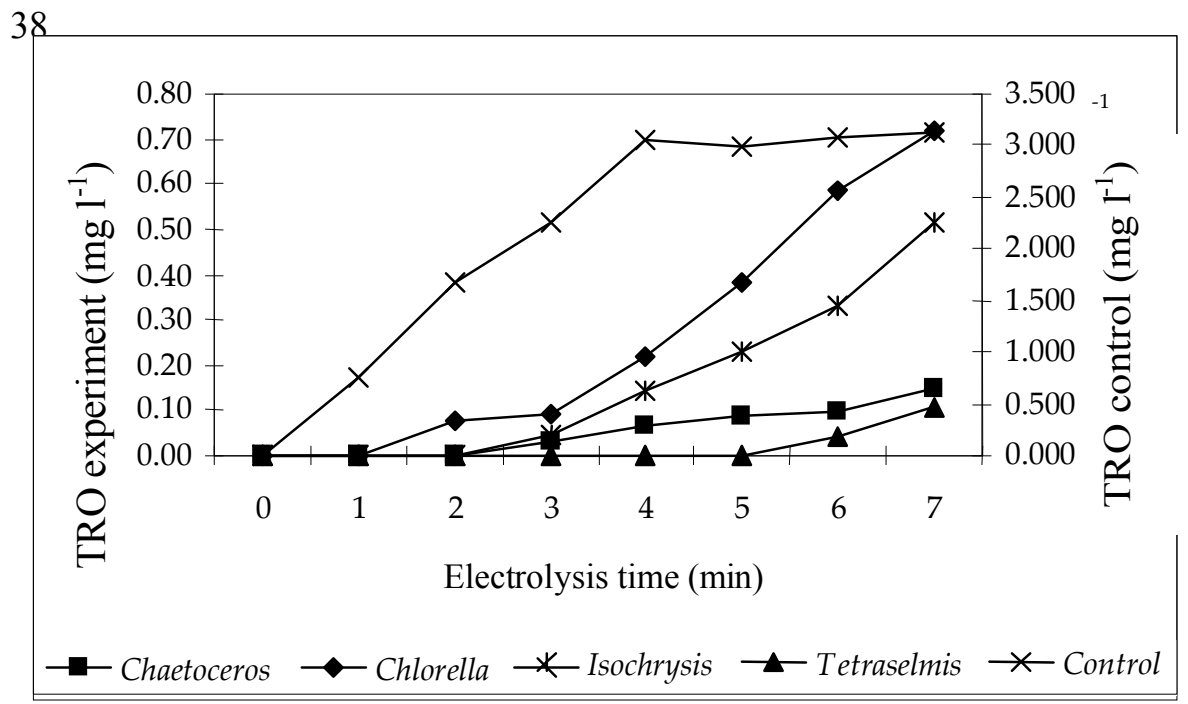

Figure 6. Total Residual Oxidant production during batch culture electrolysis with four different marine algal species. TRO was plotted against electrolysis retention time. Electrolysis reactor volume $1000 \mathrm{ml}$, Current $0.1 \mathrm{~A}$ and voltage $2.5 \mathrm{~V}$.

\section{Oxidant production}

Similar to the batch data, low TRO production was also observed during continuous electrolysis experiment. Fig. 8 shows the time course of TRO values for both species studied. The TRO values of Chlorella spp. appear to increase continuously as most algal cells were eliminated faster. However, in Isochrysis spp. the TRO values increased initially but it gradually stabilized with electrolysis time. This trend of increasing TRO production with electrolysis time is more or less similar to the pattern of chlorine production (Vlyssides et al. 2002). The Chlorella spp. also recorded slightly higher TRO values as compared toIsochrysis spp. The cell wall of Chlorella spp. with its glucoseamine double layers requires comparatively little TRO to react so that TRO readily increased with time. However, the cell walls of Isochrysis spp. consist of multi-layers of polysaccharides, which require comparatively higher TRO so that not much of it remains in the system.

\section{Conclusion}

In conclusion, electrolysis was able to reduce concentration of algal cells and this is due to lyses by the generated oxidants such as $\mathrm{HOCl}$ and $\mathrm{HOBr}$. It was also observed that the organic load preferentially reacts with TRO produced during electrolysis. By FDA and PI staining, dead and live marine algal cells can be distinguished by the nature of fluorescence emitted. Results of both batch and continuous electrolysis runs confirmed that Isochrysis spp. is more resistant than Chlorella spp. The beneficial algae Isochrysis spp. can thus be allowed to dominate by selectively limiting the growth of Chlorella spp. Electrolysis can therefore be a promising 
technology for controlling marine algae in shrimp grow-out ponds as well as in wastewater reservoirs in shrimp farming systems.

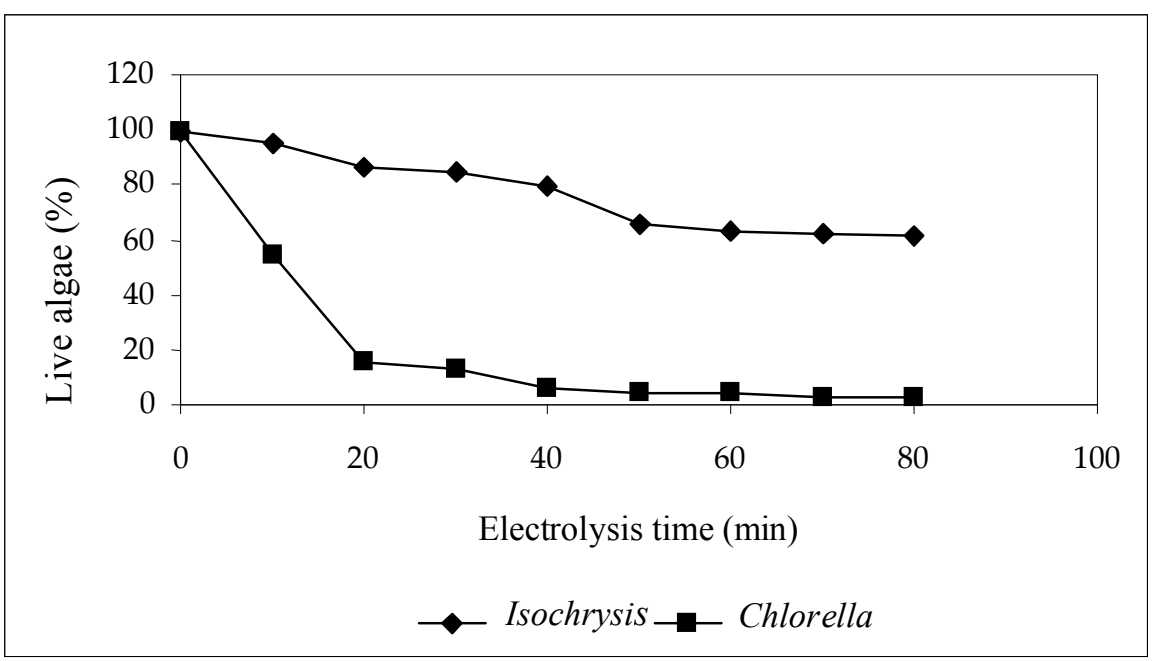

Figure 7. Time course of algal survival during continuous electrolysis experiment for Chlorella spp. and Isochrysis spp. Percent survival was estimated by FDA and PI double staining method. Algal survival was determined at every $10 \mathrm{~min}$ interval. The flow rate of medium was $160 \mathrm{ml}$ $\min ^{-1}$. The retention time was $12.5 \mathrm{~min}$.

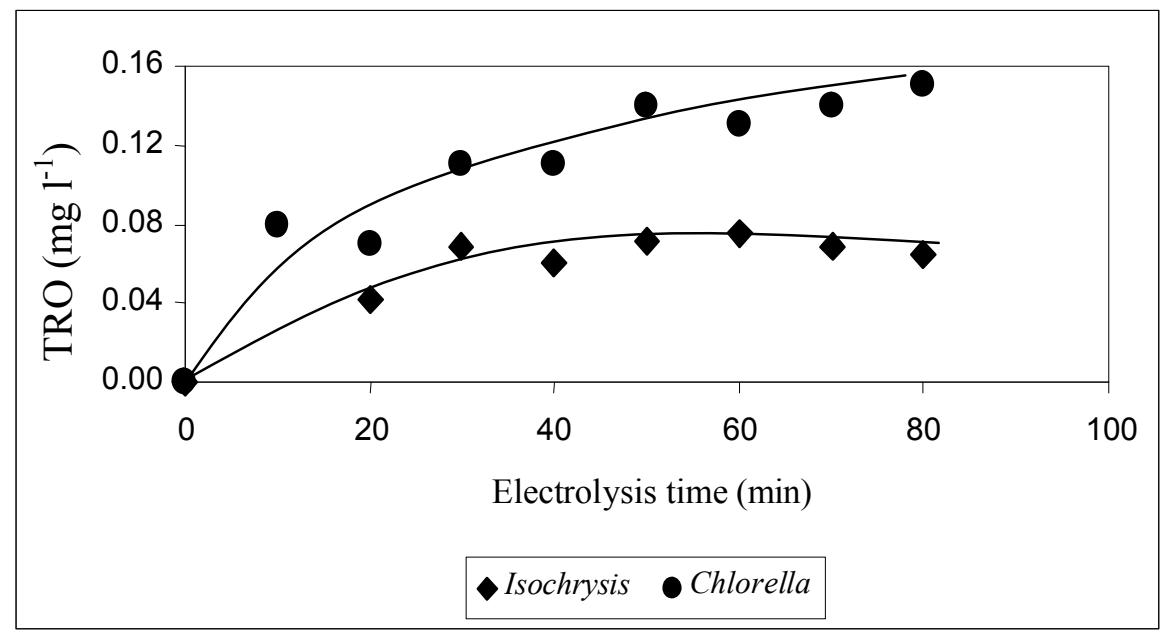

Figure 8. Time course of TRO during continuous electrolysis for the two algal species. Sampling was made at $10 \mathrm{~min}$ interval. The flow rate of

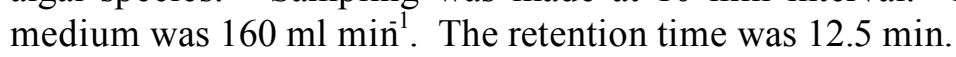




\section{References}

Alfafara C., K. Nakano, N. Nomura, I. Takeshi \& M. Matsumura 2002.

Operating and scale-up factors for the electrolytic removal of algae from eutrophied lakewater. Journal of Chemical Technology and Biotechnology. 77: 871-876.

Alfafara C., K. Takayuki, N. Nomura, M.K. Kiuchi, \& M. Matsumura 2004. Electrolytic removal of ammonia from brine wastewater: scale-up, operation and pilot-scale evaluation. Journal of Chemical Technology and Biotechnology. 79: 291-298.

Aoyagi H. and H. Tanak 1994.

Measurement of viable plant cell and protoplast concentrations with specialized fluorometer. Journal of Fermentation and Bioengineering 77: $517-521$.

Boyd, C.E. 1995.

Chemistry and efficacy of amendments used to treat water and soil quality imbalances in shrimp ponds. Proc. of the special session on shrimp farming, Aquaculture 95, W orld Aquaculture Society, Baton Rouge, Louisiana, USA 183-196.

Dunstan G.A., J.K. V olkman, S.M. Barrett \& C.D. Garland 1993.

Changes in the lipid composition and maximization of the polyunsaturated fatty acid content of three microalgae grown in mass culture. Journal of Applied Phycology. 5:71-83.

Granvil D.T. and M.F. Joe 1993.

Design Operation and Training Manual for an Intensive culture shrimp hatchery (with emphasis on Penaeus monodon and Penaeus vannamei) Sea Grant College Program, Texas A\&M University. 1187.

Hiroshi, T. 1995.

Cell wall composition and Taxonomy of symbiotic Chlorella from Paramecium and Acanthocystis. Phytochemistry. 457-459.

Jan, H.L. 2002.

The effect of Harmful Algal Blooms on Aquatic Organisms. Reviews in Fisheries Science. Florida Marine Research Institute, Florida Fish and Wildlife Conservation Commission, 100 Eighth Avenue Southeast, St. Petersbutg, FL 33701, USA. 10: Issue 2, 113-390.

Jorquera M. A., V . Gustavo, E. Mitsuru, K. Masahiko \& R. Carlos 2002. Disinfection of hatchery aquaculture systems using electrolytic waster treatment. Aquaculture. 207: 213 - 224.

Lavens P. and P. Sorgeloos 1996.

Manual on the production and use of live food for aquaculture, FAO

Technical paper, Laboratory of Aquaculture and Artemia Reference Center, University of Gent, Belgium. 1-60.

Matsumura M., N. Whanchai, V.P. Migo, H.Young, C.G. Alfafara \& N. Nomura 2001. 
Effect of algal die-off on shrimp cultivation in ponds using ozonation. In: Proceeding of the JSPS-NRCT International Symposium on Sustainable Shrimp Aquaculture and Health Management: Diseases and Environment, Tokyo University of Fisheries, Japan. 73-87.

Maria S.E., M. Gabriega \& P. Susana 2001.

UV-B effects on Antarctic Chlorella spp. cells. Journal of Photochemistry and Photobiology. 62 19-25.

Milko A.J., V. Gustavo, E. Mitsuru, K. Mashiko \& R. Carlos 2002.

Disinfection of seawater for hatchery aquaculture systems using electrolytic water treatment., Aquaculture. 207: 213-224.

Poelman E., De N. Pauw \& B. Jeurissen 1997.

Potential of electrolytic flocculation for recovery of micro-algae. Resource Conservation and Recycle. 19:1-10.

Saha N.R., T. Usami \& Y. Suzuki 2003.

A double staining flow cytometric assay for the detection of steroid induced apoptotic leucocytes in common carp Cyprinus carpio).

Developmental \& Comparative Immunology. 27: 351-363.

Sugita H., K. Hayashi, T. Asai, T. Mitsuya, K. Amanuma, C. Maruyama \& Y. Deguchi 1992.

Spectrophotometric method for determination of Total Residual

Oxidant in Seawater. The Aquaculture. 40: $45-49$.

V an den C.H., D.G. Mann \& H.M. Jahns H.M 1995.

Algae An introduction to Phycology. Published by the Press Syndicate of the University of Cambridge, The Pitt Building. Trumpington Street, Cambridge CB2 1RP, $40 \mathrm{~W}$ est $2{ }^{\circ}$ Street, New Y ork, NY 10011-4211, USA. 1-623.

Vlyssides A.G., P.K. Karlis, N. Rori \& A.A. Zorppas 2002.

Electrochemical treatment in relation to $\mathrm{pH}$ of domestic wastewater using Ti/Pt electrodes. Journal of Hazardous Materials. 95: 215-226.

V olkman J.K., G. Eglington, E.D.Corner \& J.R. Sargent 1980.

Novel unsaturated straight chain C37-C39 methyl and ethyl ketones in marine sediments and a cocolithophore Emiliania huxleyi, Advances in Organic Geochemistry, Pergamon Press, and Oxford., 219-277.

Whanchai N., V.P. Migo, C.G. Alfafara, N. Nomura, H.K. Young \& M. Matsumura 2002.

Shrimp disease disinfection and phytoplankton control of intensive shrimp pond water by electro-oxidation process. Fisheries Science. 68: 981-982.

Wolfe, M.F., 1999.

Induction of heat shock protein (hsp) 60 in Isochrysis galbana exposed to sublethal preparations of dispersant and Prudhoe Bay crude oil. Marine Environmental Resource 47: 473-489.

Y ap C.K., A. Ismail, H. Omar \& S.G.Tan 2004. 
Toxicities and tolerances of $\mathrm{Cd}, \mathrm{Cu}, \mathrm{Pb}$ and $\mathrm{Zn}$ in a primary producer (Isochrysis galbana) and in a primary consumer (Perna viridis), Environmental International. 29:1097-1104.

Zsolt T.H. and B. Arpad 2002.

Intracellular distribution of chromium and toxicity on growth in Chlorella spp. pyrenoidosa. Proceeding of the $7^{\text {th }}$ Hungarian Congress on Plant Physiology, Dept of Zoology, College of Nyaregyhaza, Nyaregyhaza, Hungary. 46 : 57-58. 